\title{
Candidaturas presidenciales en Colombia 1974-2018. Factores condicionantes de su evolución
}

JAVIER DUQue DAZA*

Artículo recibido: 5 de diciembre de 2018

Artículo aprobado: 20 de septiembre de 2019

DoI: https://doi.org/10.12804/revistas.urosario.edu.co/desafios/a.7485

Para citar este artículo: Duque Daza, J. (2020). Candidaturas presidenciales en Colombia 1974-2018. Factores condicionantes de su evolución. Desafíos, 32(2), 1-38. https://doi. org/10.12804/revistas.urosario.edu.co/desafios/a.7485

\section{Resumen}

El artículo analiza la evolución del número de candidatos presidenciales en Colombia en el periodo 1974-2018. Elpunto de partida es un enfoque neoinstitucionalista contextualizado que considera que el número de candidatos varía en función de las reglas electorales y de las dinámicas sociopoliticas del periodo. Es un estudio de caso que analiza en detalle cómo estos dos factores inciden en el numero de actores en competencia a lo largo de más de cuatro décadas. El estudio incluye un periodo de cuarenta y cuatro años y doce elecciones presidenciales y utiliza indicadores cuantittaivos para demostrar el argumento central. Las principales conclusiones del articulo son dos: la primera, bay más pluralismo y mayor competencia en las elecciones presidenciales, menos candidatos, pero estos son más relevantes. La segunda, en la evolución del número de candidatos inciden los cambios institucionales y las interacciones entre los actores en la competencia electoral; el descongelamiento de la política respecto al subperiodo 1974-1990; la

* Profesor, Universidad del Valle. Cali Colombia. Correo electrónico: jduqued86@hotmail.com. ORCID: http://orcid.org/0000-0001-9996-4835 
posterior fragmentación con dominio bipartidista; y el desplazamiento de los partidos tradicionales de sus lugares de preeminencia.

Palabras clave: elecciones; candidaturas; presidencia; competencia; Colombia.

\title{
Presidential Candidacies in Colombia 1974-2018. Political Parties, Party Systems and Political Competition
}

\begin{abstract}
The article analyzes the evolution of the number of presidential candidates in Colombia in the period 1974-2018. The starting point is a contextualized neo-institutionalist approach that considers that the number of candidates varies depending on the electoral rules and the socio-political dynamics of the period. It is a case study that analyzes in detail how these two factors affect the number of competing actors over more than four decades. The study includes a period of 44 years and 12 presidential elections and uses quantitative indicators to demonstrate the central argument. The main conclusions of the article are two. First, there is more pluralism and more competition in presidential elections, less candidates, but more relevant ones. The second, in the evolution of the number of candidates, institutional changes and interactions between the actors affect electoral competition, the thawing of the policy with respect to the 1974-1990 sub-period, the subsequent fragmentation with bipartisan dominance and the displacement of traditional parties of their places of preminence.
\end{abstract}

Keywords: elections; candidacies; presidency; competition; Colombia.

\section{Candidaturas presidenciais na Colômbia 1974-2018. Fatores condicionantes de sua evolução}

\begin{abstract}
Resumo
$O$ artigo analisa a evolução do número de candidatos presidenciais na Colômbia no periodo 1974-2018. O ponto de partida é um enfoque neoinstitucionalista contextualizado que considera que o número de candidato varia em função das regras
\end{abstract}


eleitorais e das dinâmicas sociopolíticas do período. É um estudo de caso que analisa em detalhe como estes dois fatores incidem no numero de atores em concorrência ao longo de mais de quatro décadas. O estudo inclui um periodo de 44 anos e 12 eleições presidenciais e utiliza indicadores quantitativos para demostrar o argumento central. As principais conclusões do artigo são duas. A primeira, há mais pluralismo e mais concorrência nas eleições presidenciais, menos candidatos, mas mais relevantes. A segunda, na evolução do número de candidatos incidem as mudanças institucionais $e$ as interaçôes entre os atores na concorrência eleitoral, o descongelamento da politica respeito ao subperiodo 1974-1990, a posterior fragmentação com dominio bipartidário e o deslocamento dos partidos tradicionais de seus lugares de proeminência. Palavras-chave: eleições; candidaturas; presidência; concorrência; Colômbia.

\section{Introducción}

¿De qué depende el número de candidatos que compiten en una elección presidencial? Esta pregunta remite a algunas dimensiones centrales de la política, a los partidos y a los factores que inciden en su surgimiento, a los liderazgos políticos, al nivel de competencia en los sistemas de partidos y a las instituciones bajo las cuales actúan e interactúan los partidos y los políticos.

El presente artículo se propone responder a esta pregunta en el caso de Colombia durante el periodo que abarca desde 1974 (año en que se reinstaura la competencia política después del régimen de coalición restrictivo del Frente Nacional vigente desde 1958) hasta las más recientes elecciones de 2018. Se trata de un análisis con anclaje en la literatura internacional, a partir de la cual se asume una perspectiva analítica aplicada en otros estudios similares, aunque considerando de forma crítica sus posibilidades y limitaciones. El punto de partida es que un enfoque neoinstitucionalista contextualizado constituye la mejor alternativa de análisis para comprender por qué aumenta o disminuye el número de candidatos en competencia en elecciones presidenciales. Su variación está en función de las reglas electorales que restringen o posibilitan la presencia de candidatos, pero estas no actúan en el vacío, lo hacen en contextos sociales y políticos concretos, en realidades en las cuales los clivages, las diferencias y las divisiones sociales, étnicas y religiosas se expresan a través del surgimiento de partidos políticos 


\section{4 / JAVIer Duque Daza}

o candidaturas independientes que concitan estas divisiones y las traducen en aspiraciones de acceso a la conducción política.

A diferencia de otros estudios sobre América Latina que adoptan una estrategia cuantitativa y parten de un modelo estadístico que relaciona variables en análisis comparados (Jones, 1999, 2004; Lujan, 2017), este artículo presenta un estudio de caso que parte de un encuadre analítico similar, pero que analiza en detalle cómo los factores institucionales y las dinámicas sociopolíticas se conjugan e inciden en el número de actores en competencia a lo largo de más de cuatro décadas. Así pues, se analizan doce elecciones presidenciales y se considera la evolución de las reglas electorales y el contexto sociopolítico como factores contribuyentes que permiten explicar por qué aumenta el número de candidatos, por qué surgen y se estabilizan más partidos y por qué el sistema de partidos se hace más competitivo.

A partir de los cambios en el entramado institucional y en las dinámicas sociopolíticas, se diferencian tres subperiodos: 1974-1990, durante el que se mantienen las reglas electorales, se reproduce el bipartidismo liberal-conservador, los terceros partidos son marginales y el número de candidatos es muy bajo; 1994-2002, se mantiene el bipartidismo, pero con una creciente presencia de otras fuerzas políticas dispersas y muy fragmentadas, aumenta el número de candidatos, pero siguen siendo los candidatos de origen conservador y liberal los únicos con capacidad para ganar las elecciones; y 2006-2018, cuando se dan importantes cambios institucionales y nuevas dinámicas sociopolíticas que dan origen a nuevos partidos y candidaturas relevantes con capacidad para competir, aumenta de forma significativa el número de candidatos, el sistema de partidos transita hacia el multipartidismo fragmentado y se redimensiona la competencia política.

En la medición, se utilizan tres indicadores: el número absoluto de candidatos (todos los que se inscriben y participan en las elecciones), el número de candidatos con respaldo de partidos con representación en el Congreso y el número efectivo de candidatos —este último permite ponderar a los candidatos según su peso electoral, los valora por su relevancia y descarta a los más pequeños, es decir, a quienes no 
cuentan con capacidad de coalición—. ${ }^{1}$ Además de la presentación y del análisis de la evolución de los tres indicadores se presentan y describen los resultados de las doce elecciones y la forma como se dio la competencia.

El artículo se divide en cinco partes; la primera presenta la revisión de la literatura y adopta un esquema analítico. La segunda, tercera y cuarta parte corresponden a los tres subperiodos enunciados; presentan las estadísticas de los tres indicadores, sus tendencias y especificidades; y en ellas se describe cómo se dio la competencia en cada elección. La quinta parte corresponde a la síntesis y a la conclusión.

\section{Más partidos y más candidatos: las reglas electorales y el contexto sociopolítico}

Como en otras esferas de la política, en el marco de los enfoques neoinstitucionales que parten de la premisa de que en la forma cómo se configuran los fenómenos políticos las instituciones cuentan, la respuesta a esta pregunta se puede abordar desde dos enfoques. Por una parte, quienes consideran que las instituciones (las reglas de juego, en este caso las reglas electorales) son determinantes y explican por sí mismas cuántos partidos y cuántos candidatos compiten en las elecciones y se pueden establecer generalizaciones (Duverger, 1954; Jones, 1999; Rae, 1971; Riker, 1982; Lijphart, 1994; Taagepera y Shugart, 1989; Kim \& Ohn, 1992). Por otra parte, quienes reconocen el papel y la importancia de las instituciones, pero en el marco de ciertas condiciones sociopolíticas. Este enfoque asume que existe una interacción entre la heterogeneidad social y las reglas electorales, a partir de la cual se puede explicar la presencia de un mayor número

\footnotetext{
1 Obtenido a través la adaptación del Número Efectivo de Partidos (Laakso \& Taagepera, 1979), en donde Ci es la proporción de votos de cada candidato:

$\mathrm{NEC}=\frac{1}{\sum \mathrm{Ci}^{2}}$

Esta adaptación permite ponderar el peso de cada candidato al descartar aquellos que solo obtienen resultados marginales y que participan sin tener opciones reales, en algunos casos se trata de aventuras políticas sin fundamento.
} 


\section{6 / Javier Duque Daza}

de candidatos y partidos en una sociedad, además de las reglas electorales, en las cuales entran en juego las condiciones o el contexto social y político en cada país. Por lo anterior, se dificulta en muchos casos establecer generalizaciones o estas tienen menor alcance dado que bajo las mismas instituciones podemos encontrar variaciones entre países (Rose \& Urwin, 1970; Nohlen, 1993, 1996; Nohlen \& Fernández, 1998; Cox, 1997; Moser \& Scheiner, 2012).

La segunda perspectiva es menos reductiva que la primera. Reconoce que las instituciones inciden en la política y, en este caso, en cuántos competidores hay en un sistema político, pero incluye en la explicación otras variables relacionadas con las condiciones sociopolíticas e históricas específicas de cada país. En primer lugar, considera que las reglas electorales restringen o limitan el número de actores (candidatos) en competencia, quienes pueden ser candidatos presidenciales. Aquí entra en juego una primera barrera o puerta de entrada, la norma sobre el requisito de pertenencia a un partido para poder ser candidato. En América Latina actualmente hay países que permiten candidaturas independientes y hay otros que las prohíben. ${ }^{2}$ Es claro que pueden competir candidatos partidistas, pero también los que no hacen parte de partidos o se han retirado de estos, o son independientes, se abren ventanas de oportunidades y esto se refleja en el mayor número de competidores potenciales y reales. Asimismo, el tipo de fórmula electoral incide en el número de candidatos en competencia. Un sistema de mayoría relativa incentiva menos competencia que un sistema de mayoría absoluta con segunda vuelta. Si los precandidatos asumen que es posible una segunda vuelta, tienden a participar más en la competencia por cuanto, aun sin ganar, pueden aspirar al segundo lugar y tener así otra oportunidad para obtener la victoria con solo dos candidatos. Por su parte, quienes quedan en otras posiciones pueden

\footnotetext{
2 La figura de candidaturas independientes o no partidarias como son llamadas en algunos países, existen en Bolivia, Chile, Colombia, Ecuador, Honduras, Paraguay, Perú, República Dominicana, Venezuela, Panamá y, desde el año 2010, en El Salvador y en México. En estos casos, la adopción de este tipo de candidaturas ha seguido luego de un proceso largo de demandas ciudadanas por su adopción y es resultado de una búsqueda de alternativas a los candidatos presentados por los partidos. Esta figura no existe en Argentina, Brasil, Costa Rica, Guatemala, Nicaragua ni Uruguay (De la Peza, 2007; Muñoz, 2015).
} 
tener capacidad de coalición y de negociación con los dos primeros lugares, que deben recurrir a ellos y pedirles su apoyo en la segunda vuelta (dependiendo de su proximidad ideológica, de la cercanía en programas e incluso de las simpatías personales). Así, el balotaje incentiva el número de candidatos relevantes, es decir, de aquellos que tienen capacidad de coalición y que pueden aportar a la victoria de alguno de los dos principales competidores, incluso incentiva la presencia de candidatos no viables que tienen otros objetivos diferentes al de ganar (Greenberg \& Shlomo, 1985; Palfrey, 1989; Shugart \& Carey, 1992; Myerson \& Weber, 1993; Mainwaring \& Shugart, 1997; Shugart \& Argueta Sandoval, 2007; Jones, 1999, 2004; Chasquetti, 2001). ${ }^{3}$ Una tercera regla que tiende a incentivar las candidaturas se refiere a las elecciones concurrentes para presidente y Congreso que favorecen especialmente a los partidos pequeños que tienen poca opción de ganar, pero que asumen que un candidato presidencial favorece sus aspiraciones para obtener curules. Son candidatos no viables, pero que utilizan la elección presidencial para un objetivo distinto, como posicionarse o alcanzar representación parlamentaria (Jones, 1999; Luján, 2017).

No obstante, mientras que algunas reglas electorales inciden en el aumento del número de candidatos en competencia, otras constriñen y regulan la competencia. En tal sentido, las élites que diseñan o rediseñan los sistemas electorales tienden también a regular y ajustar la oferta y el número de candidatos al inducirlos a su retiro si se elevan los costos (Cox, 1997; Jones, 1999). Si existe reelección inmediata y en las respectivas elecciones el presidente titular se postula nuevamente, esto inhibe el número de candidatos pues la competencia frente a los recursos del poder con que cuenta el mandatario dificultan la competencia y el mandatario aparece como el favorito para ganar (Jones, 1999, 2004). Si la financiación procede de recursos públicos (parcial o totalmente) las candidaturas y los partidos pueden ser más exitosas pues se facilita su capacidad para competir, aunque las barreras electorales altas para acceder a estos recursos contrarrestan estas facilidades (Luján, 2017). Asimismo, cuando se establecen requisitos de inscripción para

\footnotetext{
3 En América latina cinco países mantienen el sistema de mayorías relativas a una vuelta: Honduras, México, Panamá, Paraguay y Venezuela.
} 


\section{I Javier Duque Daza}

candidaturas no partidistas como el respaldo de firmas, cuya recolección conlleva tiempo, apoyo, dinero, se levantan barreras de acceso a las candidaturas. De igual forma, cuando se distribuyen espacios publicitarios en medios estatales acordes con la representación del partido en el Congreso o con sus resultados electorales en recientes elecciones se limitan las posibilidades para nuevos candidatos (esto implica el favorecimiento a los candidatos partidistas respecto a los independientes). Así, si un arreglo institucional incentiva o no el mayor número de candidatos en competencia, depende de la forma cómo se combinen las reglas que favorecen o restringen la competencia.

En segundo lugar, se asume que las condiciones sociopolíticas también inciden en el número de partidos y candidatos que compiten. Aquí se suele considerar el grado de heterogeneidad social y, en relación con esta, las características del sistema de partidos. Es claro que en sistemas bipartidistas el número de candidatos relevantes con capacidad de competir es de dos, aunque pueda haber candidatos minoritarios, incluso algunos testimoniales (que no compiten para ganar sino con otros fines, como dejar constancia de su oposición, o para poder hacer coaliciones si hay segunda vuelta). En sistemas multipartidistas el número de candidatos depende de las posibilidades y restricciones de las reglas, pero también del número absoluto de partidos y estos reflejan divisiones sociales, sectores sociales emergentes, diferencias y rupturas en la sociedad. El sistema político tendrá más partidos solo si tiene muchos clivages ${ }^{4}$ y estos se han politizado, en el sentido de dar origen a organizaciones políticas que expresan la presencia de sectores sociales, étnicos, religiosos. Dicho sistema debe contar, a su vez, con un sistema electoral lo suficientemente permisivo para permitir su surgimiento sobre dichos clivages (Cox, 1997; Luján, 2017). Se considera que las identidades sociales generan intereses comunes, simpatías partidistas e identidades colectivas que hacen que la elección

\footnotetext{
4 Se refiere a fracturas o divisiones sociales segmentadas que expresan los niveles de heterogeneidad social en una sociedad. Stefano Bartolini y Peter Mair (1990) destacan tres características: (a) la división que separa a las personas por sus atributos sociales derivados de su etnia, religión, ubicación en la estructura social; (b) quienes hacen parte de estas divisiones tienen identidad colectiva, hacen parte de una comunidad de interés por los vínculos existentes; (c) se expresan en organizaciones, en acciones colectivas que tienden a estabilizarse.
} 
de un partido tenga connotaciones de clase social, religiosas, sectoriales, étnicas. Si hay un número mayor de clivajes, esto se refleja en el número de partidos que existe en la sociedad (Grum, 1958; Lipset \& Stein, 1967; Harmel \& Robertson, 1985; Horowitz, 1985; Ordershook \& Shversova, 1994).

Puede haber tantos candidatos como partidos, y si se permiten candidatos independientes y las reglas son permisivas, puede haber más candidatos. No obstante, también entra en juego la polarización ideológica. A mayor nivel de polarización ideológica, menor número de candidatos en competencia por cuanto los partidos y candidatos tienden a agruparse en torno a los polos de las diferencias ideológicas y el espacio central pierde fuerza y candidatos (Sani \& Sartori, 1983). Asimismo, entran en juego los alineamientos del electorado y la estabilidad de las preferencias. Cuando hay mayor inestabilidad en el sistema de partidos y en la competencia hay más posibilidades para nuevos competidores; esto incentiva las candidaturas aventureras o que no sopesan las verdaderas opciones de éxito (Luján, 2017).

En suma, a partir de los dos conjuntos de factores, el sistema político tendrá más partidos solo si tiene muchas fracturas sociales que se hayan politizado y que cuenten, a su vez, con normas electorales flexibles para la creación de partidos. De esta manera, el sistema político puede presentar candidatos y candidatos independientes que puedan competir.

En el caso de Colombia en el periodo que abarca los años 1974-2018 se dio el tránsito del bipartidismo al multipartidismo y aumentó de forma significativa el número de candidatos, así como los candidatos con probabilidades de éxito. Durante el subperiodo 1974-1990 se conjugaron reglas electorales más restrictivas con clivages sociales y heterogeneidad social que no se habían politizado de forma organizativa, lo que permitió la reprodución de un formato bipartidista con bajo número de candidatos absolutos y relativos (candidatos efectivos). En el periodo 1994-2018 se conjugaron reglas menos restrictivas, los clivages sociales se concretaron en organizaciones políticas y se dio un proceso de escisiones en los dos partidos históricos: 
Liberal y Conservador. Si bien ambos partidos expresan diferencias ideológicas e intereses divergentes en la clase política, este proceso de esciciones se reflejó en el aumento del número de partidos y de candidatos viables. En ambos subperiodos hicieron presencia candidaturas testimoniales que no eran viables, pero que competían con fines distintos a los de ganar.

\section{Bipartidismo, democracia limitada y bajo número de candidatos: 1974-1990}

En el subperiodo 1974-1990 el entramado institucional en Colombia estaba orientado a la reproducción del bipartidismo, a la vez que cerraba las puertas para que surgieran otras fuerzas políticas. Se trataba de una democracia limitada, oligárquica, restringida, en la que la heterogeneidad social no se expresaba en organizaciones politizadas. Además del férreo control de los mecanismos y de los recursos del poder por parte de los partidos Liberal y Conservador; del clientelismo favorecido por las reglas vigentes; y de la ausencia de espacios y de mecanismos de participación, en las elecciones competían muy pocos candidatos y a la presidencia se llegaba solo si se hacía parte de la élite del poder.

Además, el sistema electoral era muy restrictivo. No permitía la inscripción de candidaturas presidenciales independientes; ${ }^{5}$ el presidente se elegía mediante mayoría relativa; no había reelección presidencial inmediata; y las elecciones de Congreso y Presidencia no eran concurrentes. De hecho, hasta las elecciones de 1986 no existió la financiación pública de los partidos y esta era parcial y beneficiaba a los dos grandes partidos que concentraban el electorado en más del $90 \%$ en promedio. ${ }^{6}$ Además, otras instituciones favorecían la reelección (indefinida) de los congresistas adscritos a los partidos Liberal

\footnotetext{
5 El Código Electoral de 1986 establecía que en la solicitud de inscripción debía hacerse mención expresa del partido o movimiento político por el cual se inscribía una candidatura y que los inscriptores debían hacer ante el respectivo funcionario electoral, bajo juramento, la declaración de que estaban afiliados a ese partido o movimiento político. Para tal juramento, los candidatos debían firmar en el memorial de aceptación de la candidatura (art. 96).

6 Estatuto Básico de los Partidos Políticos, Ley 58 de 1985, art. 12.
} 
y Conservador que aportaban el electorado desde los departamentos a sus candidatos presidenciales liberales y conservadores. Había acumulación de mandatos; los congresistas manejaban el empleo público, los nombramientos (era muy bajo el número de funcionarios de carrera administrativa estables) y accedían a los recursos del Estado a través del pork barrel por los auxilios parlamentarios, una partida del presupuesto de la Nación que estos distribuían o asignaban de forma discrecional en sus respectivos departamentos. Además, las fundaciones, organizaciones, juntas comunales, colegios y escuelas, entre otros, debían demostrar estar del lado de los congresistas de sus respectivos departamentos para que los incluyeran en un listado que proporcionaba cada congresista y que se inscribía en la comisión del presupuesto en el Congreso (Hartlyn, 1989). ${ }^{7}$ Por último, vale la pena mencionar que los congresistas manejaban un electorado cautivo a través de extendidas redes de clientelismo que se activaban en elecciones presidenciales y frente a las cuales resultaba difícil competir. ${ }^{8}$

En teoría, la prohibición de la reelección inmediata del presidente sería un estímulo para que aumentara el número de candidatos (Jones, 2004), pero los dos partidos dominantes controlaban de forma directa o indirecta los recursos del poder y estos se ponían en función del mantenimiento en sus posiciones de poder. En los partidos Liberal y Conservador existía un círculo reducido de políticos nacionales que podían aspirar a ser nominados por sus partidos a la presidencia, los denominados jefes naturales, un pequeño grupo de políticos con gran poder e influencia en sus partidos y en la política nacional: en el Partido

\footnotetext{
7 Desde 1886 se estableció como una de las funciones del Congreso "fomentar las empresas útiles o benéficas dignas de estímulos y apoyo" (art. 76) para lo cual se generaba una partida en el presupuesto nacional. Posteriormente, mediante el acto legislativo nro. 1 de 1945, se trató de reglamentar su uso al señalarse que debían fomentarse este tipo de empresas, pero con "estricta sujeción a los planes y programas correspondientes". El monto era acordado e incluido en el presupuesto y se dividía por el número de departamentos y, dentro de cada uno de estos, por el número de congresistas. Mediante esta gestión los congresistas podían atender sus zonas de influencia electoral. Sin embargo, en muchos casos los congresistas crean sus propias fundaciones u organizaciones que canalizan y distribuyen los recursos, o estos se apropian para las campañas electorales, esto según los cálculos de Jonathan Hartlyn (1989).

8 Sobre el clientelismo en este subperiodo ver: Losada (1984); Díaz (1986); Uprimny (1989); Leal y Dávila (1990).
} 
Liberal Carlos Lleras Restrepo (presidente en 1966-1970 y aspirante a la candidatura de nuevo en 1974 y en 1978), Julio César Turbay Ayala (presidente 1978-1982), Alfonso López Michelsen (presidente 19741978 y de nuevo candidato en 1982), Virgilio Barco (precandidato en 1982 y presidente en 1986-1990) y en el partido Conservador Álvaro Gómez Hurtado (candidato en 1974, precandidato en 1978 y en 1982, y candidato nuevamente en 1990) y Belisario Betancur (candidato en 1970 y en 1978, y presidente en 1982). Con el respaldo de Carlos Lleras Restrepo surgió el político Luis Carlos Galán (candidato disidente en 1982 y precandidato en 1990).

La contracara del predominio absoluto del bipartidismo y de su reducido círculo de jefes naturales, en un contexto institucional adverso fue que otros partidos no logaron conformar partidos que pudieran disputarle espacios de poder a los tradicionales. La izquierda no logró constituirse en un medio de acceso masivo de nuevos miembros del Congreso de la República y todos sus candidatos fueron testimoniales, simbólicos, en procura de cierta figuración en espacios públicos para debatir ideas. Su débil capacidad de movilización electoral estaba asociada a tres factores centrales: primero, la dinámica clientelar bipartidista, en combinación con la presencia del recurso simbólico de la identificación partidista de la mayoría de los colombianos con los partidos Liberal y Conservador; ${ }^{9}$ lo que aseguraban cotos de caza, feudos de anclaje electoral frente a los cuales resultaba muy difícil competir. Segundo, la orientación política de los partidos de izquierda; el Partido Comunista Colombiano (PCC) y el Movimiento Obrero Independiente Revolucionario (MOIR) preferían espacios de acción política diferentes al electoral y atribuían un papel secundario al escenario parlamentario, tomado como actividad complementaria a otras formas de acción política. Así pues, las elecciones eran más bien una alternativa para hacer propaganda, denuncias y para

\footnotetext{
9 A través de la socialización política y la tradición durante este subperiodo se mantenían fuertes lazos de la población con los partidos Liberal y Conservador. Los datos de 1980 mostraban que el 65,8\% de los colombianos se identificaba con un partido político y de estos el $54 \%$ se autodefinían como liberales, el 38\% conservadores y el $8 \%$ de otros partidos (Losada \& Vélez, 1982).
} 
"concienciar a la población". Tercero, por sus concepciones ideológicas ortodoxas los dos partidos y las organizaciones eventuales de izquierda se ubicaban en posiciones ideológicamente extremas, con lo cual no representaban un factor de atracción para sectores de la población que no se alineaban con el bipartidismo, pero que tampoco veían en la izquierda una alternativa política viable. La abstención era muy alta, por lo que los electores se alineaban con el bipartidismo - por clientelismo y/o adhesiones clientelistas - o no votaban. ${ }^{10}$

Además de la izquierda ninguna otra división social se expresaba electoralmente ni en elecciones para Congreso ni para la Presidencia. Aunque había organizaciones indígenas que aglutinaban a la mayoría de estas minorías ${ }^{11}$ como la Organización Nacional Indígena de Colombia (ONIC) — creada en 1982—, ${ }^{12}$ así como organizaciones de afrodescendientes, ${ }^{13}$ como el Movimiento Nacional Cimarrón, ${ }^{14} \mathrm{y}$ organizaciones religiosas protestantes que se expandieron desde la década de 1970 — y que solo desde 1990 empezaron a incursionar en los escenarios electorales-, ninguna de estas constituía una fuerza representativa. ${ }^{15}$

10 Las abstenciones en las elecciones presidenciales de este subperiodo fueron del 41,9\% en 1974; del 54,9\% en 1978; del 53,4\% en 1982; del 53,7\% en 1986 y del 52,2\% en 1990. En promedio fue del $51,2 \%$, es decir, de más de la mitad del censo electoral.

11 En 1990, la población indígena representaba cerca de 1200000 de personas, un 3,5\% de la población.

12 La fundación de la ONIC fue el resultado del proceso de reorganización autónoma del movimiento indígena en Colombia iniciado por los tres pueblos constituyentes del Consejo Regional Indígena del Cauca (CRIC) en la década de 1970, y apoyado por líderes de otras comunidades. Su propósito era darle una identidad al movimiento indígena y denunciar la violencia de la que eran objeto. En 1982 se formalizó la organización con cuarenta y un organizaciones asociadas.

13 En 1990, la población afrodescendiente estaba estimada al menos en $12 \%$ del total de habitantes, es decir, en cerca de 4100000 de personas.

14 El Movimiento Nacional CimArRon se fundó en Buenaventura, Valle del Cauca, el 15 de diciembre de 1982, por el Círculo de Estudios de la Problemática de las Comunidades Afrocolombianas (SOWETO).

15 Desde la década de 1970, aparecieron muchas organizaciones religiosas que idearon formas de proselitismo, con grandes infraestructuras y el acceso a medios de comunicación. $\mathrm{Si}$ bien estas organizaciones se habían mantenido al margen de la política partidista, esto cambió desde finales de la década de 1980, y en 1990 se presentó por primera vez un candidato a elecciones que reivindicaba su pertenencia a una organización religiosa protestante. En el marco 
Como se observa en la tabla 1, el número de candidatos presidenciales en este subperiodo es muy bajo. Aunque el número absoluto de candidatos es alto para tratarse de un sistema de partidos bipartidista, cuando lo comparamos con el número de candidatos de partidos con representación en el Congreso se reduce drásticamente, más aún si tenemos en cuenta el muy alto índice de concentración de escaños en los partidos Liberal y Conservador (la suma de los porcentajes de congresistas que concentraban los dos partidos son en promedio del $94,8 \%$ en las cinco elecciones). Esto se reduce aún más si se recurre al número efectivo de candidatos, considerado el indicador más prominente para medir la competencia entre candidatos en una elección (Cox, 1997; Taagepera \& Shugart, 1989; Jones, 2004). Así pues, se pondera el peso de los candidatos con base en su electorado. El promedio del subperiodo es de 2,4, lo cual indica un bipartidismo un poco atenuado por la presencia eventual de otros candidatos minoritarios, pero sin oportunidades reales para ganar las elecciones.

Tabla 1. Número de candidatos presidenciales 1974-1990

\begin{tabular}{|c|c|c|c|c|}
\hline Año & $\begin{array}{c}\text { Número } \\
\text { absoluto de } \\
\text { candidatos }\end{array}$ & $\begin{array}{c}\text { Número de } \\
\text { candidatos de } \\
\text { partidos con } \\
\text { escaños en el } \\
\text { Congreso }\end{array}$ & $\begin{array}{c}\text { Número } \\
\text { efectivo de } \\
\text { candidatos }\end{array}$ & $\begin{array}{c}\text { Índice de } \\
\text { concentración } \\
\mathbf{( \% )}\end{array}$ \\
\hline 1974 & 5 & 3 & 2,10 & 87,7 \\
\hline 1978 & 5 & 2 & 2,30 & 96,3 \\
\hline 1982 & 5 & 3 & 2,50 & $98,7 *$ \\
\hline 1986 & 5 & 3 & 2,11 & 94,1 \\
\hline 1990 & 12 & 5 & 3,03 & 87,0 \\
\hline Promedio & 6,4 & 3,2 & 2,4 & 92,7 \\
\hline
\end{tabular}

Fuente: elaboración del autor con base en estadísticas electorales de la Registraduría Nacional del Estado Civil, años respectivos.

* Incluye a los dos candidatos liberales, Alfonso López Michelsen por el oficialismo y Luis Carlos Galán por el Nuevo Liberalismo, así como al candidato del partido Conservador.

Los candidatos Liberal y Conservador eran los únicos con expectativas reales de ganar pues contaban con recursos económicos propios

de la convocatoria a las elecciones para la Asamblea Nacional Constituyente, las comunidades protestantes compitieron y ganaron dos de los setenta escaños de la Asamblea (Duque, 2010). 
y del Estado, el respaldo de los grandes gremios de la economía que los financiaban y se apoyaban en las maquinarias de los políticos departamentales y municipales que los respaldaban con sus redes de electores de clientela, alimentadas con recursos del Estado. Eventualmente hubo terceros candidatos de partidos que participaban en las elecciones, pero sus votaciones eran marginales. Dadas las mayorías del partido Liberal en el Congreso, ser candidato por este partido era ser presidente. Así ocurrió en este periodo, en 1974, 1978 y en 1986. En 1982 el liberalismo se dividió con la candidatura disidente de Luis Carlos Galán del Nuevo Liberalismo, pero sumados los dos candidatos liberales superan la votación del candidato de origen conservador que ganó las elecciones: 51,9\% frente al 46,8\% (tabla 2).

Solo en las elecciones de 1974 un candidato diferente al bipartidismo superó el 5\% de la votación total. María Eugenia Rojas, a nombre de la Alianza Nacional Popular (ANAPO), consiguió el 9,5\% de los votos y el candidato de la Unión Nacional de Oposición (UNO), Hernando Echeverry Mejía, respaldado por los diversos grupos y partidos de izquierda, alcanzó el 2,7\% de la votación. En las siguientes elecciones de 1978 la izquierda obtuvo con Julio César Pernía el 1,9\% de los votos; en 1982 el candidato Gerardo Molina solo obtuvo el 1,2\% de los votos; en 1986 el candidato de la Unión Patriótica (UP), Jaime Pardo Leal, alcanzó la más alta votación de la izquierda hasta ese momento con el 4,5\% y en 1990 Antonio Navarro Wolf, del nuevo partido Alianza Democrática M-19, alcanzó el 12,5\% de la votación.

En 1990, hubo una situación especial de una coyuntura crítica que explica el relativo incremento de candidatos, en términos absolutos de 12 , pero en ponderación de su peso electoral se reduce a 3,03 según el número efectivo de candidatos, lo que indica que se mantuvo la muy alta concentración bipartidista $(87 \%)$. En medio de la violencia que vivía el país por las acciones de los diferentes grupos guerrilleros y de las mafias del narcotráfico y del paramilitarismo se presentaron dos candidatos de organizaciones de izquierda que fueron asesinados. El primero fue el candidato presidencial Bernardo Jaramillo Ossa, de Partido UP, surgido del proceso de paz entre las FARC-EP y el gobierno de Belisario Betancur (1982-1986), asesinado en marzo 22 de 1990 
Tabla 2. Colombia: Resultados de las elecciones presidenciales 1974-1990

\begin{tabular}{|c|c|c|c|c|}
\hline \multirow{2}{*}{ Año } & \multicolumn{2}{|c|}{ Contendores } & \multicolumn{2}{|c|}{ Primera vuelta } \\
\hline & Candidatos & Partidos & Votos & $\%$ \\
\hline \multirow{5}{*}{1974} & Alfonso López Michelsen & Liberal & 2929729 & 56,3 \\
\hline & Álvaro Gómez Hurtado & Conservador & 1634879 & 31,4 \\
\hline & María Eugenia Rojas & ANAPO & 492162 & 9,4 \\
\hline & Otros (dos candidatos) & Otros partidos & 142778 & 2,9 \\
\hline & Total & & 5199548 & 100 \\
\hline \multirow{4}{*}{1978} & Julio César Turbay Ayala & Liberal & 2503681 & 49,5 \\
\hline & Belisario Betancur Cuartas & Conservador & 2366620 & 46,8 \\
\hline & Otros (tres candidatos) & Otros & 187624 & 3,7 \\
\hline & Total & & 5057925 & 100 \\
\hline \multirow{5}{*}{1982} & Belisario Betancur Cuartas & Conservador & 3189587 & 46,8 \\
\hline & Alfonso López Michelsen & Liberal & 2797786 & 41,0 \\
\hline & Luis Carlos Galán & Nuevo Liberalismo & 746024 & 10,9 \\
\hline & Otros (dos candidatos) & Otros partidos & 83368 & 1,3 \\
\hline & Total & & 6816765 & 100 \\
\hline \multirow{5}{*}{1986} & Virgilio Barco Vargas & Liberal & 4214510 & 58,3 \\
\hline & Álvaro Gómez Hurtado & Conservador & 2588050 & 35,8 \\
\hline & Jaime Pardo Leal & Unión Patriótica (UP) & 328752 & 4,5 \\
\hline & Otros (dos candidatos) & Otros partidos & 90506 & 1,4 \\
\hline & Total & & 7221818 & 100 \\
\hline \multirow{6}{*}{1990} & César Gaviria Trujillo & Liberal & 2891808 & 48,8 \\
\hline & Álvaro Gómez Hurtado & Movimiento de Salvación Nal. & 1433913 & 24,2 \\
\hline & Antonio Navarro Wolf & Alianza Democrática M-19 & 754740 & 12,7 \\
\hline & Rodrigo Lloreda Caicedo & Conservador & 735374 & 12,4 \\
\hline & Otros (ocho candidatos) & Otros partidos & 108712 & 1,9 \\
\hline & Total & & 5924547 & 100 \\
\hline
\end{tabular}

Fuente: elaboración del autor con base en estadísticas de la Registraduría Nacional del Estado Civil

* Incluye oficialismo liberal y Nuevo Liberalismo, sectores de un mismo partido.

(ya en 1987 había sido asesinado Jaime Pardo Leal, candidato en 1986). El segundo, un mes después, fue Carlos Pizarro Leongómez de la Alianza Democrática M-19, organización creada con la reinserción de la guerrilla del M-19 en 1989 en el gobierno de Virgilio Barco (1986-1990) y al cual reemplazó Antonio Navarro Wolf. Para 
ese momento ya habían asesinado al precandidato del partido Liberal Luis Carlos Galán en agosto de 1989.

En las elecciones de este año participaron cuatro candidatos con capacidad de movilización electoral: César Gaviria Trujillo, por el Partido Liberal; Antonio Navarro Wolf, por la Alianza Democrática M-19 y dos candidatos surgidos de la división del Partido Conservador: Rodrigo Lloreda Caicedo, por el sector oficialista, y Álvaro Gómez Hurtado, por el Movimiento de Salvación Nacional. Los otros ocho candidatos eran testimoniales, candidatos ficticios que, en conjunto, sumaron menos del $2 \%$ del total de los votos.

\section{Nueva Constitución política, mantenimiento del bipartidismo y fragmentación de las terceras fuerzas políticas}

En el segundo momento o subperiodo se prolongó el predominio bipartidista en el Congreso y los partidos Liberal y Conservador siguieron siendo competitivos en las elecciones (1994 y 1998), aunque desde el año 2002 se empezaron a enunciar cambios que se consolidaron en el siguiente subperiodo. Bajo las nuevas reglas electorales instituidas por la Constitución de 1991 el sistema se hizo más pluralista y esto se reflejó en el crecimiento sustancial de los diferentes indicadores del número de candidatos. No obstante, aún se mantuvo el dominio de la dirigencia de origen liberal y conservadora y las terceras fuerzas no lograron aún ser competitivas pues actuaban de forma dispersa sin liderazgos aglutinadores. Debido a la ausencia de regulación y de sanciones se presentaron numerosos candidatos irrelevantes.

En Colombia, la orientación incluyente de la Asamblea Nacional Constituyente de 1990-1991 permitió establecer un conjunto de reglas que propiciaron una mayor apertura democrática. Estas reglas, junto con la consolidación de la organización política de algunos sectores de la sociedad, revirtieron en el surgimiento de nuevos partidos que incursionaron en las elecciones y contaron con nuevos espacios y oportunidades para divulgar sus iniciativas y para impulsar a sus 
líderes. Aunque, de hecho, no contaban con posibilidades de acceder a la Presidencia.

Respecto al subperiodo anterior, las nuevas reglas incluyeron una gran flexibilidad para la creación de partidos (ahora solo se requiere el respaldo de 50000 firmas); se permitió la inscripción de candidatos independientes pues no había que pertenecer a un partido para postularse; se estableció la segunda vuelta en elecciones presidenciales a partir de 1994 si un candidato no obtenía en la primera vuelta la mitad más uno de los votos; se prohibió la reelección del presidente; se amplió la financiación estatal parcial de los partidos y de las campañas, aunque se estableció un esquema de reposición de votos que favorece a los candidatos de partidos ya establecidos; el Estado empezó a financiar de forma más amplia a los partidos y también las consultas internas y empezó a hacer reposición de dinero según los votos que obtengan los precandidatos. También se introdujeron otros cambios como la circunscripción única para Senado, las circunscripciones especiales para las minorías indígenas en el Senado y las minorías afrodescendientes en la Cámara; y se redujo el tamaño del Congreso. ${ }^{16}$

Bajo el nuevo entramado institucional más incluyente, algunas de las divisiones sociales vigentes se empezaron a expresar políticamente. Surgieron partidos conformados por comunidades cristianas que accedieron al Congreso y que entraron a jugar un papel activo en el apoyo a candidatos presidenciales o que comenzaron a postular sus propios candidatos. Igual sucedió con las minorías étnicas que se hicieron más visibles y contaron con espacios en las corporaciones públicas; también las minorías políticas de izquierda y de otras agrupaciones contaron con mayor probabilidad de acceso al Senado a través de la agregación de votos en diversos departamentos, en los que se redujo del dominio absoluto de las clientelas partidistas. Durante estos se pasó del cerramiento político casi absoluto del subperiodo anterior, a una apertura

\footnotetext{
16 El Senado pasó de 114 a 102 miembros, dos se eligen por circunscripción especial indígena. La Cámara pasó de 199 escaños a 161, además de cinco escaños adicionales por circunscripciones especiales: dos curules para comunidades afrodescendientes, una para indígenas, uno para colombianos en el exterior y uno para las minorías políticas.
} 
que llevó a la atomización partidista y a la hiperfragmentación, de tal forma que en las elecciones para Congreso de 1991 hubo veintitrés organizaciones políticas con representación en el Congreso, veinticuatro en 1994, treinta en 1998 y, en el 2002, se llegaron a sumar cuarenta y cinco, aunque solo en estas últimas las facciones internas liberales y conservadoras optarían por separarse de forma definitiva de estos. ${ }^{17}$ A su vez, la financiación de campañas permitió a nuevos candidatos contar con apoyos que antes eran inaccesibles.

Así pues, el número de candidatos aumentó; se pasó de un promedio de 6,4 entre 1974-1990, a un promedio de 14 entre 1994-2002. ${ }^{18}$ Desde 1994 aumentó y pasó a 18 candidaturas, aunque en las elecciones posteriores disminuyó y hubo más candidatos que antes de la reforma (en 1998 fueron 13 candidatos y en 2002 fueron 11). Igual sucedió con el número de candidatos cuyos partidos contaban con escaños en el Congreso, el cual pasó de 3,2 a 5,3 en promedio y también creció el número efectivo de candidatos (tabla 3).

En las elecciones presidenciales de 1994 el partido Liberal mantuvo sus tradicionales mayorías en el Congreso y, por tercera vez consecutiva, ganó la presidencia con el exministro y exsenador Ernesto Samper Pizano. Por primera vez se aplicó en el país el balotaje en unas elecciones muy reñidas frente al candidato de origen conservador Andrés Pastrana Arango, exalcalde de Bogotá. También por primera vez compitió un candidato procedente de un grupo guerrillero desmovilizado, Antonio Navarro Wolf, por la Alianza Democrática M-19, partido que había sido protagonista central en la Asamblea Nacional Constituyente y que estaba en declive después de su alta votación en las elecciones de Congreso de 1991. Además, estas elecciones estuvieron permeadas por la financiación ilegal del Cartel de Cali a una parte de la campaña del candidato liberal y a un amplio número de congresistas de este partido. Samper tuvo que dedicar gran parte de su gobierno a

\footnotetext{
17 La fuente es la Registraduría Nacional del Estado Civil, estadísticas electorales años respectivos.

18 Los datos sobre número y evolución de candidaturas se incluyen parcialmente en (Duque, 2018).
} 
Tabla 3. Número de candidatos presidenciales 1974-2002

\begin{tabular}{|c|c|c|c|c|}
\hline Año & $\begin{array}{c}\text { Número } \\
\text { absoluto de } \\
\text { candidatos }\end{array}$ & $\begin{array}{c}\text { Número de candidatos } \\
\text { presidenciales de partidos con } \\
\text { escaños en el Congreso }\end{array}$ & $\begin{array}{c}\text { Número } \\
\text { efectivo de } \\
\text { candidatos }\end{array}$ & $\begin{array}{c}\text { Índice de } \\
\text { concentración } \\
\mathbf{( \% )}\end{array}$ \\
\hline 1974 & 5 & 3 & 2,10 & 87,7 \\
\hline 1978 & 5 & 2 & 2,30 & 96,3 \\
\hline 1982 & 5 & 3 & 2,50 & $98,7 *$ \\
\hline 1986 & 5 & 3 & 2,11 & 94,1 \\
\hline 1990 & 12 & 5 & 3,03 & 87,0 \\
\hline Promedio & $\mathbf{6 , 4}$ & $\mathbf{3 , 2}$ & $\mathbf{2 , 4}$ & $\mathbf{9 2 , 7}$ \\
\hline 1994 & 18 & 4 & 2,45 & 90,3 \\
\hline 1998 & 13 & 6 & 3,21 & 68,9 \\
\hline 2002 & 11 & 6 & 2,47 & 86,4 \\
\hline Promedio & $\mathbf{1 4 , 0}$ & $\mathbf{5 , 3}$ & $\mathbf{2 , 7}$ & $\mathbf{8 1 , 9}$ \\
\hline
\end{tabular}

Fuente: elaboración del autor con base en estadísticas electorales de la Registraduría Nacional del Estado Civil, años respectivos.

* Incluye a los dos candidatos liberales Alfonso López Michelsen por el oficialismo y Luis Carlos Galán, por el Nuevo Liberalismo, así como al candidato del Partido Conservador.

defenderse de las acusaciones por esta financiación en el denominado "Proceso 8000". ${ }^{19}$ En estas elecciones aún se presentaron numerosos candidatos aventureros, sin ningún respaldo electoral y algunos de ellos buscando publicidad para proyectarse hacia otros cargos.

Después del turbulento Proceso 8000, las elecciones de 1998 significaron una gran derrota para el partido Liberal. Al exministro, excongresista y exconstituyente Horacio Serpa Uribe lo derrotó Andrés Pastrana Arango, quien contó con el apoyo de un sector del Partido Liberal que se separó de este partido por considerar que era una organización corrupta y permeada por el narcotráfico. Aunque en primera vuelta triunfó Serpa Uribe, el resultado se revirtió y en la segunda ronda ganó el candidato conservador, apuntalado por su promesa de paz y por su acercamiento previo a la comandancia de la guerrilla de las FARC-EP. También por primera vez una tercería lograba una votación significativa con la candidata Noemí Sanín. Esta procedía del Partido Conservador, pero rompió con este partido y logró movilizar a algunos sectores no

\footnotetext{
19 Hay una amplia bibliografía al respecto, entre otros véase: Thoumi (1993); Cañón (1998);
} Gutiérrez (2000); Beltrán y Salcedo (2008); Cepeda (2011); Duncan (2014); Duque (2017). 
bipartidistas obteniendo el 26,9\% de los votos. De hecho, estuvo cerca de pasar a segunda vuelta. En conjunto los candidatos procedentes de los partidos tradicionales concentraron más del $95 \%$ de los votos. De nuevo, hubo otros diez candidatos irrelevantes. Las normas vigentes aún no sancionaban las aventuras electorales.

Si bien se mantenían las mismas reglas de juego instituidas por la Constitución de 1991, las dinámicas internas de los partidos Liberal y Conservador eran centrífugas y su tradicional división interna empezó a eclosionar a partir de 2002. Muchos de los movimientos y facciones de estos partidos se autonomizaron, de tal forma que, al descontar sus curules en las elecciones de 2002, quedaron por primera vez en la historia del país en condición de minorías (ambos partidos sumaron en el Senado el 51,1\% de las curules y en la Cámara el 49,4\%). Este año ganó Álvaro Uribe Vélez (exintegrante del partido Liberal y, en tal sentido, considerado un político tradicional bipartidista), candidato que se presentó como independiente por la etiqueta Primero Colombia, con el respaldo de una amplia alianza multipartidista que incluyó al Partido Conservador que, por primera vez desde 1942, no presentó candidato propio y a numerosos políticos liberales que desertaron de su partido. ${ }^{20}$ Estas elecciones se realizaron en pleno proceso de dominio de grupos paramilitares en más de veinte de los treinta y dos departamentos, y, posteriormente, diversos testimonios revelaron su incidencia directa en los resultados electorales debido a la financiación ilegal y a la movilización de electores a través de la coacción (Medina, 1990; López \& Sevillano, 2008; La bibibierta, 2010; Duque, 2017).

\footnotetext{
20 Muchos congresistas liberales apoyaron al candidato disidente Álvaro Uribe Vélez y se incorporaron a la coalición de gobierno. Hubo numerosas deserciones y surgieron nuevos partidos altamente personalizados bajo la dirección de congresistas que entraron a participar de la distribución de los recursos derivados de su posición en el nuevo gobierno, los principales fueron Cambio Radical y el Partido Social de Unidad Nacional, además de otros partidos que desaparecieron tras las investigaciones y condenas por sus nexos con grupos paramilitares, como Colombia Democrática, Apertura Liberal, Colombia Viva, Movimiento Nacional Progresista o Movimiento Popular Unido. Lo mismo sucedió con algunos movimientos internos conservadores que se independizaron y que reagruparon a congresistas y políticos regionales como Equipo Colombia-Alas, el Unionismo o el Conservatismo Independiente.
} 
Tabla 4. Colombia: Resultados de las elecciones presidenciales 1994-2014

\begin{tabular}{|c|c|c|c|c|c|c|}
\hline \multirow[t]{2}{*}{ Año } & \multicolumn{2}{|c|}{ Contendores } & \multicolumn{2}{|c|}{ Primera vuelta } & \multicolumn{2}{|c|}{ Segunda vuelta } \\
\hline & Candidatos & Partidos & Votos & $\%$ & Votos & $\%$ \\
\hline \multirow{5}{*}{1994} & $\begin{array}{l}\text { Ernesto Samper } \\
\text { Pizano }\end{array}$ & Liberal & 2623210 & 45,3 & 3773366 & 51,3 \\
\hline & $\begin{array}{l}\text { Andrés Pastrana } \\
\text { Arango }\end{array}$ & Conservador & 2604771 & 45,0 & 3576781 & 49,7 \\
\hline & $\begin{array}{l}\text { Antonio Navarro } \\
\text { Wolf }\end{array}$ & $\begin{array}{l}\text { Compromiso } \\
\text { Colombia }\end{array}$ & 219241 & 3,8 & & ----- \\
\hline & $\begin{array}{l}\text { Otros (quince } \\
\text { candidatos) }\end{array}$ & Otros partidos & 278994 & 5,9 & & --- \\
\hline & Total & & 5726216 & 100 & 7350147 & 100 \\
\hline \multirow{6}{*}{1998} & Horacio Serpa & Liberal & 3634823 & 34,6 & 5620719 & 48,0 \\
\hline & Andrés Pastrana & Conservador & 3607945 & 34,3 & 6086507 & 52,0 \\
\hline & Noemí Sanín & Si Colombia & 2824735 & 26,9 & & ---- \\
\hline & Harold Bedoya & Fuerza Colombia & 192173 & 1,8 & & ---- \\
\hline & $\begin{array}{l}\text { Otros (nueve } \\
\text { candidatos) }\end{array}$ & Otros partidos & 247870 & 2,4 & & ---- \\
\hline & Total & & 10507546 & 100 & 11707226 & 100 \\
\hline \multirow{9}{*}{2002} & Álvaro Uribe & Primero & 5862655 & 54,0 & No hubo & ---- \\
\hline & Vélez & Colombia & & & & \\
\hline & Horacio Serpa & Partido Liberal & 3514779 & 32,4 & & \\
\hline & Uribe & & & & & \\
\hline & Luis Eduardo & Frente Social y & 680245 & 6,2 & & \\
\hline & Garzón & Político & & & & \\
\hline & Noemí Sanín & Sí Colombia & 641884 & 5,9 & & \\
\hline & $\begin{array}{l}\text { Otros (siete } \\
\text { candidatos) }\end{array}$ & Otros partidos & 155966 & 1,5 & & \\
\hline & Total & & 10855529 & 100 & & \\
\hline
\end{tabular}

Fuente: elaboración del autor con base en estadísticas de la Registraduría Nacional del Estado Civil.

La desarticulación y desagregación que se produjo en los partidos Liberal y Conservador favoreció la candidatura de Uribe Vélez pues en la medida en que fue avanzando en las encuestas, los congresistas se fueron desplazando hacia su campaña como una expresión de pragmatismo y de oportunismo que terminó por relegar a los partidos Liberal y Conservador. Álvaro Uribe ganó en primera vuelta, seguido 
del candidato liberal Horacio Serpa Uribe, quien sumó su segunda derrota consecutiva. La candidata Noemí Sanín de nuevo se presentó por una tercería y en esta ocasión su votación fue marginal, de igual forma el candidato de la izquierda unificada Luis Eduardo Garzón solo obtuvo el 6,2\% de los votos. Estos cuatro candidatos fueron la expresión de un mayor pluralismo y los resultados evidenciaron la presencia de nuevos realineamientos del electorado. Asimismo, como las normas no incluían aún ninguna sanción para las aventuras electorales, el número de candidatos ficticios fue muy alto.

\section{Nuevas reglas, multipartidismo, nuevos actores, más candidatos relevantes}

En el subperiodo 2006-2018, se modificó de forma sustancial el entramado institucional en el país y las nuevas reglas continuaron favoreciendo el pluralismo, a la vez que se orientaron a racionalizar la competencia y a limitar el número de partidos que mostraba síntomas de desinstitucionalización y alta fragmentación. Asimismo, algunos de los clivages sociales se politizaron y se expresaron electoralmente lo que generó dinámicas internas en el bipartidismo que se tradujeron en escisiones en los partidos Liberal y Conservador, y en el surgimiento de nuevos partidos. Estos tres factores incidieron para que se redujera el número absoluto de candidatos presidenciales; que desaparecieran las candidaturas aventureras e irrelevantes, a la vez que para que aumentara la competitividad en las elecciones (mayor número de candidatos con representación en el Congreso y mayor número efectivo de candidatos).

Desde al año 2003, se aprobaron en el país sucesivas reformas institucionales que introdujeron importantes cambios en el sistema electoral. En respuesta a la desarticulación de los partidos y a la atomización del sistema de partidos, después de las elecciones de 2002 las aproximaciones entre las diversas bancadas en el Congreso y la evaluación de los problemas generados por las normas vigentes y las dinámicas internas de los partidos hicieron posible una nueva reforma política que constituyó un cambio en los congresistas, reacios 
a cambiar las normas por el riesgo de perder posiciones de poder. El Congreso elegido para el periodo 2002-2006 estuvo conformado por cuarenta y tres partidos, muchos de ellos pequeños y efímeros y, a diferencia del pasado, los partidos Liberal y Conservador ya no eran mayoritarios. En estas condiciones las negociaciones avanzaron y se concretaron en el Acto legislativo 01 de $2003 .{ }^{21}$ Con la reforma, se prohibió la doble militancia (los movimientos que mantenían su doble condición de autónomos pero con vínculos con los partidos Liberal y Conservador, debían decidir si se constituían en partidos independientes o desaparecían); se estableció el umbral electoral, lo que tuvo una gran incidencia en el número de partidos reconocidos (solo los partidos que obtuvieran un mínimo de votos equivalente al 2\% del total de votos de cada elección para Senado y la mitad del cociente electoral para la Cámara de representantes podían aspirar a la asignación de escaños) y se establecieron las listas únicas. Además, de forma contradictoria con lo anterior, se estableció el voto preferente que permite la agregación de votos mediante negociaciones de los dirigentes regionales con cada partido, dando paso, de hecho, a la reproducción del faccionalismo interno y a numerosos subpartidos; también, se modificó la fórmula electoral, se pasó del sistema Hare al de D'Hont en la modalidad de cifra repartidora.

La reforma tuvo impactos importantes sobre el sistema político, entre ellos la modificación de la fragmentación de los partidos Liberal y Conservador. La amplia y creciente división partidista contribuyó al tránsito del bipartidismo con fragmentación interna a un multipartidismo producto de fusiones y divisiones. Muchas fracciones internas dieron origen a nuevos partidos y otras se reincorporaron a las etiquetas nacionales. Otros pequeños partidos desaparecieron y la izquierda se aglutinó desde el 2005 en el Polo Democrático Alternativo.

\footnotetext{
21 Previamente había fracasado el referendo convocado por el Gobierno de Álvaro Uribe Vélez y que incluía numerosas reformas. El mínimo requerido para la aprobación era de 6267443 (un potencial de 25069 773) y solo la primera pregunta se aprobó, es decir, la que hacía referencia a los impedimentos para ejercer cargos y postularse a elecciones de quienes hubieran sido condenados, en cualquier tiempo, por la comisión de delitos que afecten el patrimonio del Estado. Esta obtuvo 6293807 votos (Véase Vélez, Ossa \& Montes, 2006; Duque, 2010).
} 
Estas reformas empezaron a tener incidencia en las elecciones locales de 2003 y para Congreso desde el 2006. Al siguiente año se aprobó la reforma que restableció la reelección presidencial inmediata (Acto legislativo 01 de 2004). Las mayorías en el Congreso que hacían parte de la coalición de Gobierno aprobaron la reforma en medio de una gran polémica y de forma ilegal, lo cual condujo a prisión a tres excongresistas y a dos ministros por el delito de cohecho. Asimismo, con la Ley 996 de 2005 se estableció que para inscribir candidatos a la Presidencia los grupos significativos de ciudadanos deben reunir un número de firmas válidas equivalentes al $3 \%$ del número total de los votos válidos depositados por los ciudadanos en la anterior elección presidencial. Para que el Estado reponga en dinero por número de votos obtenidos el candidato debe obtener al menos el $4 \%$ del total de votos.

Estos dos cambios institucionales tuvieron efectos en las siguientes elecciones. En los comicios de 2006 se redujeron los candidatos absolutos (7), el número de candidatos con partidos con representación en el Congreso (5) y el número efectivo de candidatos volvió a ser similar al del subperiodo del bipartidismo $(2,21)$. Con un presidente muy popular, ${ }^{22}$ que contaba con el respaldo de amplias mayorías en el Congreso y que se apoyaba en todos los recursos del poder para respaldar su propia reelección, la competencia resultaba especialmente difícil. Los partidos tradicionales debilitados quedaron por fuera de la competencia (el Partido Conservador decidió no presentar candidato por segunda vez y el liberalismo postuló por tercera vez a Horacio Serpa Uribe, quien solo obtuvo el 11,8\% de los votos), la izquierda unida en torno al candidato Carlos Gaviria del PDA se ubicó por primera vez en segundo lugar y Uribe obtuvo una muy holgada victoria. Los candidatos irrelevantes, que ahora podían ser sancionados económicamente, se redujeron solo a tres. El bipartidismo ya era cosa del pasado y Uribe se constituía en el principal actor político del país, con un gran poder y un periodo prolongado de ocho años de gobierno.

22 Entre mayo de 2002 y mayo de 2006, antes de las elecciones, Álvaro Uribe tuvo altos porcentajes de favorabilidad en las encuestas: el valor más bajo fue del $66 \%$ y el más alto del $78 \%$ (El País, 2006). 


\section{I JaVier Duque Daza}

Aunque desde el 2002 numerosos partidos aparecieron y desaparecieron, otros se estabilizaron y han hecho parte de la competencia ya en el marco de un sistema multipartidista. Cambio Radical (creado en 1998) se separó definitivamente del Partido Liberal; en 2005 se creó el Partido Social de Unidad Nacional, conformado por políticos procedentes del liberalismo y del conservatismo; en 2014 se creó el Centro Democrático por parte del expresidente Álvaro Uribe Vélez y su círculo de apoyos procedentes de los partidos Liberal, Conservador y el Partido Social de Unidad Nacional. El panorama se completó con el partido Opción Ciudadana (antes Partido de Integración Nacional y Convergencia Ciudadana), el Movimiento Decentes (creado por disidentes del Polo Democrático Alternativo) y pequeños partidos regionales que aparecen y desaparecen.

En este tercer subperiodo, el número de candidatos disminuyó respecto a las elecciones precedentes (1994-2002), pero aumentó respecto al subperiodo de bipartidismo controlado por élites cerradas (1974-1990). Un cambio fundamental, además del desplazamiento definitivo de los partidos Liberal y Conservador, fue el surgimiento de otras alternativas; una mayor competencia; una mayor presencia de candidatos fuertes de la izquierda y nuevas divisiones en las élites políticas. Un mayor número de candidatos dejaron de ser marginales electoralmente, comenzaron a contar con representación en el Congreso y hasta el momento muchos han ocupado cargos dentro del Estado o ya cuentan con trayectorias políticas importantes. Es decir, se pasó de candidaturas testimoniales a otras con mayor capacidad de movilización electoral, con respaldo de organizaciones partidistas consolidadas y con mayor capacidad de coalición. Además del aumento en número, hubo un cambio cualitativo en las candidaturas. 
Tabla 5. Indicadores de pluralismo en las elecciones presidenciales 1974-2018

\begin{tabular}{|c|c|c|c|c|}
\hline Año & $\begin{array}{c}\text { Número } \\
\text { absoluto de } \\
\text { candidatos }\end{array}$ & $\begin{array}{c}\text { Número de } \\
\text { candidatos } \\
\text { presidenciales de } \\
\text { partidos con escaños } \\
\text { en el Congreso }\end{array}$ & $\begin{array}{c}\text { Número efectivo } \\
\text { de candidatos }\end{array}$ & $\begin{array}{c}\text { Índice de } \\
\text { concentración } \\
\text { (\%) }\end{array}$ \\
\hline 1974 & 5 & 3 & 2,10 & 87,7 \\
\hline 1978 & 5 & 2 & 2,30 & 96,3 \\
\hline 1982 & 5 & 3 & 2,50 & 98,7 \\
\hline 1986 & 5 & 3 & 2,11 & 94,1 \\
\hline 1990 & 12 & 5 & 3,03 & 87,0 \\
\hline Promedio & $\mathbf{6 , 4}$ & $\mathbf{3 , 2}$ & $\mathbf{2 , 4}$ & $\mathbf{9 2 , 7}$ \\
\hline 1994 & 18 & 4 & 2,45 & 90,3 \\
\hline 1998 & 13 & 6 & 3,21 & 68,9 \\
\hline 2002 & 11 & 6 & 2,47 & 86,4 \\
\hline Promedio & $\mathbf{1 4 , 0}$ & $\mathbf{5 , 3}$ & $\mathbf{2 , 7}$ & $\mathbf{8 1 , 9}$ \\
\hline 2006 & 7 & 5 & 2,21 & 84,3 \\
\hline 2010 & 9 & 8 & 3,48 & 68,0 \\
\hline 2014 & 5 & 5 & 4,79 & 55,0 \\
\hline 2018 & 7 & 6 & 3,10 & 64,4 \\
\hline Promedio & $\mathbf{7 , 0}$ & $\mathbf{6 , 0}$ & $\mathbf{3 , 4}$ & $\mathbf{6 7 , 9}$ \\
\hline
\end{tabular}

Fuente: elaboración del autor con base en estadísticas electorales de la Registraduría Nacional del Estado Civil, años respectivos.

* Incluye a los dos candidatos liberales, Alfonso López Michelsen por el oficialismo y Luis Carlos Galán, por el Nuevo Liberalismo, así como al candidato del Partido Conservador.

Las siguientes elecciones de 2010, 2014 y 2018 presentaron el mayor número de candidatos efectivos de las cuatro décadas analizadas. Hubo dos nuevos cambios institucionales que incidieron en la competencia y en el número de candidatos: se estableció que el gobierno debía entregar un anticipo a los partidos nuevos que nunca habían participado en elecciones, lo cual potenciaba a candidatos importantes que contaran con una importante proyección y pudieran conseguir los avales bancarios respectivos. Asimismo, se regularon más las consultas internas y se crearon las consultas interpartidistas que permitían a candidatos de partidos diferentes hacer coaliciones y acordar fórmulas 
para elegir al candidato, esto permitía fortalecer algunos candidatos y agregar electorados de diverso origen. ${ }^{23}$

Se había consolidado el sistema multipartidista, los partidos Liberal y Conservador pasaron a ser minorías y emergieron nuevos liderazgos. En 2010 ganó el candidato Juan Manuel Santos (también exintegrante del Partido Liberal) del Partido Social de Unidad Nacional, con el respaldo del expresidente Álvaro Uribe Vélez y su círculo de apoyos. Estimulados por la mayor financiación y por la ausencia de una macro-candidatura, hubo más candidatos. El segundo lugar fue para el exalcalde de Bogotá del Partido Alianza Verde, Antanas Mockus. Este año aumentó a 9 el número absoluto de candidatos, a 8 los candidatos con partidos con representación en el Congreso y el número efectivo de candidatos fue de 3,48. En la segunda vuelta la gran mayoría de candidatos hicieron coalición con Juan Manuel Santos; para algunos ese era el real propósito de sus candidaturas: poder tener capacidad de coalición en búsqueda de posicionamiento. Germán Vargas Lleras, de Cambio radical, ocupó el tercer lugar y como retribución a su adhesión fue nombrado Ministro del Interior en 2010 y, en 2012, Ministro de Vivienda. También Rafael Pardo, del Partido Liberal, quien ocupó el sexto lugar y también entró en la coalición, fue nombrado Ministro de Trabajo en 2011 y designado alcalde encargado de Bogotá cuando fue destituido temporalmente Gustavo Petro. Este último, quien ocupó el cuarto lugar en la elección presidencial, tomó la candidatura como una plataforma para aspirar a la alcaldía de la capital.

\footnotetext{
23 Mediante el Acto legislativo 01 de 2009, se propuso fortalecer la organización interna de los partidos lo que reafirmó la prohibición de la doble militancia. Así pues se determinó que quien, siendo miembro de una corporación pública, decidiera presentarse a la siguiente elección por un partido distinto deberá renunciar a la curul al menos un año antes. También se determinó que los partidos deben organizarse de forma democrática; que para combatir la corrupción deben responder por los avales que concedan y que pueden ser sancionados. Además, se modificó el umbral o barrera electoral; se limitó el monto de los gastos de los partidos y candidatos en las campañas, así como los aportes privados; se estableció la "silla vacía” y se determinó que no se reemplazaría a los miembros de una corporación pública si es proferida orden de captura dentro de un proceso por delitos relacionados con la pertenencia, promoción o financiación de grupos armados ilegales, del narcotráfico o por delitos de lesa humanidad.
} 
En 2014, los dos primeros lugares fueron para Juan Manuel Santos, del Partido Social de Unidad Nacional, y para Óscar Iván Zuluaga, del nuevo partido Centro Democrático, un partido de reciente formación. Fueron elecciones muy competitivas con segunda vuelta y los comicios con mayor número relativo de candidatos. El número absoluto de candidatos fue de 5 , todos de partidos con representación en el Congreso y todos con capacidad de coalición, a tal punto que el número efectivo de candidatos fue de 4,79, casi igual al número absoluto. Aunque Santos se postulaba a la reelección, en este caso este hecho no inhibió el número de candidatos. El expresidente Uribe Vélez creó su propio partido en oposición al Gobierno de Santos y a él se sumaron numerosos políticos exliberales, exconservadores y ex-Partido Social de Unidad Nacional. Su propósito era recapturar el poder pues Santos había gobernado con programas y políticas opuestas a las del expresidente, que lo había impulsado y respaldado. Su candidato Óscar Iván Zuluaga ganó en la primera vuelta, pero Santos ganó en segunda vuelta, apoyado en la coalición con la izquierda del Polo Democrático Alternativo y su candidata Clara López Obregón, el Partido Liberal y la Alianza Verde. En estas elecciones también hubo candidatos con propósitos diferentes a los de ganar, que tomaron sus candidaturas como un medio para llegar a otras posiciones: Clara López ocupó el cuarto lugar, aportó al triunfo de Santos y fue nombrada Ministra de Trabajo y Enrique Peñalosa tomó la elección como un trampolín a la alcaldía de Bogotá, la cual ganó en 2015.

Finalmente, las elecciones de 2018 también fueron muy competitivas y se presentaron 7 candidatos, 6 de ellos con partidos con representación en el Congreso y un número efectivo de candidatos de 3,10. Hubo tres candidatos fuertes y otros tres con capacidad de coalición. Como Santos cumplía su segundo periodo, se abrieron nuevas oportunidades para otros candidatos y hubo mayor competencia. En medio de la inestabilidad política y partidista, la radicalización de sectores de derecha opuestos al proceso de negociaciones del Gobierno con la guerrilla de las FARC-EP, el Partido Social de Unidad Nacional, ganador en 2010 y 2014, ahora no presentó candidato, afectado por su división interna y por la ausencia de liderazgos nacionales. Tampoco el Partido Conservador presentó candidato propio y dividió su apoyo 
entre los candidatos Iván Duque Márquez del Centro Democrático (candidato elegido mediante una consulta interpartidista en la que participaron dos candidatos de origen conservador, el exprocurador destituido Alejandro Ordoñez y la exministra de defensa Marta Lucía Ramírez) y Germán Vargas Lleras, de Cambio Radical, quien adoptó como estrategia presentarse con el respaldo de firmas). De nuevo se presentó Gustavo Petro, pero ya no por el Polo Democrático Alternativo, del cual se había separado, sino por su propio movimiento, Colombia Humana, a través del respaldo de firmas. Sergio Fajardo fue el candidato de la coalición del Polo Democrático Alternativo, Alianza Verde y el movimiento Compromiso Ciudadano (producto de una consulta interpartidista), y Humberto de la Calle fue postulado por el ahora marginal Partido Liberal. También hubo dos candidaturas minoritarias de iglesias cristianas, José Antonio Trujillo (de Todos Somos Colombia) y Viviane Morales (de Somos Región Colombia), quien finalmente se retiró, pero alcanzó a salir en el tarjetón electoral (después recibió como retribución a su aporte a la campaña con sus potenciales electores la embajada de Colombia en París).

No hubo ganador en primera vuelta y en la segunda la mayoría de los partidos ubicados en la derecha del espectro ideológico se aglutinaron en torno al candidato del Centro Democrático (Conservador, Liberal, Cambio Radical, Partido Social de Unidad Nacional y los dos partidos cristianos) para competir con el candidato de la izquierda, Gustavo Petro, quien recibió apoyos parciales del Polo Democrático Alternativo, la Alianza Verde y otros pequeños partidos. Ganó la coalición de derecha con Iván Duque Márquez.

Así, entre 2006-2018, se redimensionó la competencia por la presidencia en Colombia. En medio de reformas institucionales que favorecieron la competencia y la presencia de nuevos candidatos desaparecieron desde el 2006 las candidaturas irrelevantes; se redistribuyó el electorado; se equilibró más el sistema multipartidista con menos partidos más fuertes. También se dieron cambios en los contenidos ideológicos, con una mayor radicalización de la derecha, un tema que trasciende el alcance de este artículo. 
Tabla 6. Colombia: Resultados de las elecciones presidenciales 1994-2014

\begin{tabular}{|c|c|c|c|c|c|c|}
\hline \multirow{2}{*}{ Año } & \multicolumn{2}{|c|}{ Contendores } & \multicolumn{2}{|c|}{ Primera vuelta } & \multicolumn{2}{|c|}{ Segunda vuelta } \\
\hline & Candidatos & Partidos & Votos & $\%$ & Votos & $\%$ \\
\hline \multirow{11}{*}{2006} & Álvaro Uribe & Primero Colombia & 7397835 & 62,3 & No hubo & ----- \\
\hline & Vélez & & & & & \\
\hline & Carlos Gaviria & Polo Democrático & 2613157 & 22,0 & & \\
\hline & Díaz & Alternativo & & & & \\
\hline & Horacio Serpa & Liberal & 1404275 & 11,8 & & \\
\hline & Uribe & & & & & \\
\hline & Antanas Mockus & Alianza Social & 146583 & 1,2 & & \\
\hline & & Indígena & & & & \\
\hline & Otros (tres & Otros partidos & 76603 & 2,7 & & \\
\hline & candidatos) & & & & & \\
\hline & Total & & 11638453 & 100 & & \\
\hline \multirow{12}{*}{2010} & Juan Manuel & Partido Social de & 6758539 & 46,5 & 9004221 & 71,5 \\
\hline & Santos & Unidad Nacional & & & & \\
\hline & Antanas Mockus & Partido Verde & 3120716 & 21,5 & 3588819 & 29,5 \\
\hline & Germán Vargas & Cambio Radical & 1471377 & 10,1 & & ----- \\
\hline & Lleras & & & & & \\
\hline & Gustavo Petro & Polo Democrático & 1329512 & 9,1 & ------------ & ---- \\
\hline & & Alternativo & & & & \\
\hline & Noemí Sanín & Partido Conservador & 892323 & 6,1 & ------------ & ---- \\
\hline & Rafael Pardo & Partido Liberal & 636624 & 4,4 & & ----- \\
\hline & Otros (tres & Otros partidos & 81705 & 2,3 & ---------- & ----- \\
\hline & candidatos) & & & & & \\
\hline & Total & & 14290796 & 100,0 & 12593040 & 100 \\
\hline
\end{tabular}


32 I JaVier Duque Daza

\begin{tabular}{|c|c|c|c|c|c|c|}
\hline \multirow{2}{*}{ Año } & \multicolumn{2}{|c|}{ Contendores } & \multicolumn{2}{|c|}{ Primera vuelta } & \multicolumn{2}{|c|}{ Segunda vuelta } \\
\hline & Candidatos & Partidos & Votos & $\%$ & Votos & $\%$ \\
\hline \multirow{7}{*}{2014} & $\begin{array}{l}\text { Juan Manuel } \\
\text { Santos }\end{array}$ & Unidad Nacional & 3310794 & 25,7 & 7839342 & 51,0 \\
\hline & $\begin{array}{l}\text { Óscar Iván } \\
\text { Zuluaga }\end{array}$ & Centro Democrático & 3769005 & 29,3 & 6917001 & 49,0 \\
\hline & $\begin{array}{l}\text { Marta Lucía } \\
\text { Ramírez }\end{array}$ & Partido Conservador & 1997980 & 15,5 & ---- & ----- \\
\hline & Clara López & Polo Democrático & 1958518 & 15,2 & ----------- & ----- \\
\hline & Obregón & Alternativo & & & & \\
\hline & Enrique Peñalosa & Alianza Verde & 1064758 & 8,3 & ----------- & ----- \\
\hline & Total & & 12101055 & 100,0 & 14756343 & 100,0 \\
\hline \multirow{12}{*}{2018} & Iván Duque & -Centro & 7569693 & 39,1 & 10373080 & 54,0 \\
\hline & Márquez & $\begin{array}{l}\text { Democrático- } \\
\text { Coalición }\end{array}$ & & & & \\
\hline & Gustavo Petro & -Colombia Humana & 4851254 & 25,1 & 8034189 & 41,8 \\
\hline & Sergio Fajardo & -Compromiso & 4589696 & 23,7 & -------- & \\
\hline & & Ciudadano-Coalición & & & --- & \\
\hline & Germán Vargas & -Mejor Vargas & 1407840 & 7,3 & & \\
\hline & Lleras & $\begin{array}{l}\text { Lleras-Cambio } \\
\text { Radical }\end{array}$ & & & ---- & \\
\hline & Humberto de la & -Liberal & 399180 & 2,1 & ------ & \\
\hline & Calle & & & & ---- & \\
\hline & Jorge Antonio & -Todos Somos & 75614 & 0,4 & ---- & \\
\hline & Trujillo & Colombia & & & ---- & \\
\hline & Viviane Morales & $\begin{array}{l}\text {-Somos Región } \\
\text { Colombia }\end{array}$ & 41458 & 0,2 & --------- & \\
\hline
\end{tabular}

Fuente: elaboración del autor con estadísticas de la Registraduría Nacional del Estado Civil.

\section{Conclusiones}

Este artículo partió de la pregunta ¿de qué depende el número de candidatos que compiten en una elección presidencial? La respuesta enunciada y desarrollada fue que dependen de dos conjuntos de factores: de las reglas de juego electorales y de las dinámicas sociopolí- 
ticas asociadas con el surgimiento de nuevos partidos políticos y de nuevos liderazgos. A partir de estos dos factores se analizaron doce elecciones a lo largo de cuarenta y cuatro años y el análisis permite extraer cuatro conclusiones:

Hay reglas que inciden más en la limitación del número de candidatos en elecciones presidenciales, por ejemplo, la fórmula electoral con mayoría relativa; la prohibición de candidaturas independientes; la financiación estatal limitada; la existencia de umbral electoral para legalizar candidaturas (en número de firmas que las respalden) o para financiar las candidaturas independientes: o la reelección presidencial inmediata. Sin embargo, existen también reglas que favorecen un mayor número de candidatos y un mayor pluralismo como la fórmula electoral con doble vuelta; la aceptación de candidaturas independientes de los partidos; la financiación pública extendida y previa; la ausencia de umbrales; la no reelección presidencial; y la posibilidad de consultas internas interpartidistas.

En sociedades heterogéneas socialmente, si las divisiones se politizan y se expresan en la competencia política, surgen nuevos partidos y nuevos liderazgos que canalizan las aspiraciones de sectores de la sociedad. Así ocurrió en Colombia desde la década de 1990.

Es claro que el neoinstitucionalismo constituye un enfoque que permite una aproximación a la comprensión de las dinámicas políticas. No obstante, las reglas de juego no actúan en el vacío ni producen por sí mismas transformaciones en la realidad por cuanto hay dinámicas sociopolíticas que coadyuvan a las transformaciones, en este caso a un mayor pluralismo, una mayor competencia y cambios en los sistemas de partidos.

En Colombia, durante el subperiodo 1974-1990, se combinaron reglas electorales restrictivas y la no politización de los clivages sociales, el resultado fue un formato bipartidista con exclusión de terceras fuerzas políticas y un bajo número de candidatos. Las reglas vigentes impedían una mayor competencia y limitaban el pluralismo. Entre 1994-2002 se prolongó el predominio bipartidista en el Congreso y 
los partidos Liberal y Conservador siguieron siendo competitivos en las elecciones (1994 y 1998), aunque desde el año 2002 se empezaron a enunciar cambios que se consolidaron en el siguiente subperiodo. Bajo las nuevas reglas electorales instituidas por la Constitución de 1991 el sistema se hizo más pluralista y esto se reflejó en el crecimiento sustancial en los diferentes indicadores del número de candidatos. No obstante, aún se mantiene el dominio de la dirigencia de origen liberal y conservadora, y las terceras fuerzas no logran aún ser competitivas pues actuaban de forma dispersa sin liderazgos aglutinadores. Además, debido a la ausencia de regulación y de sanciones se presentaban numerosos candidatos irrelevantes. Entre 2006 y 2018 los cambios en las reglas electorales, la proyección de nuevos liderazgos políticos y las dinámicas organizativas de los partidos y de diversos sectores políticos incidieron en el aumento significativo del número de candidatos, en una mayor competencia, en más pluralismo y en cambios en el panorama partidista.

\section{Referencias}

Bartolini, S., \& Mair, P. (1990). Identity, Competition and Electoral Availability. The Stabilization of European Electorates 1885-1985. Cambridge: Cambridge University Press.

Beltrán de León, I., \& Salcedo-Albarán, E. (2008). Narcotráfico y parapolítica en Colombia, 1980-2007, evolución del capital social perverso. Borradores de Método Nro. 50.

Cañón, L. (1998). La crisis. Cuatro años a bordo del gobierno de Samper. Bogotá: Planeta.

Cepeda Ulloa, F. (2011). Narcotráfico, financiación politica y corrupción. Bogotá: Ecoe Ediciones.

Chasquetti, D. (2001). Elecciones presidenciales mayoritarias en América Latina. Revista América Latina Hoy, 29, 31-51.

Código Electoral de Colombia, Decreto 2241 de 1986 [Código] (1986). Diario Oficial 37571

Cox, G. (1997). Making Votes Count: Strategic Coordination in the World's Electoral Systems. Nueva York: Cambridge University Press

De la Peza, J. (2007). Candidaturas independientes. En D. Nohlen et. al. (Comps). Tratado de derecho electoral comparado de América Latina (pp. 613- 
623). México D. F.: Instituto Interamericano de Derechos Humanos, Universidad de Heidelberg, International IDEA, Tribunal Electoral del Poder Judicial de la Federación, Instituto Federal Electoral, Fondo Cultura Económica.

Díaz Uribe, E. (1986). El clientelismo en Colombia: Un estudio exploratorio. Bogotá: Áncora Editores.

Duncan, G. (2014). Más que plata o plomo: El poder político del narcotráfico en Colombia y México. Bogotá: Debate.

Duque Daza, J. (2010). Las comunidades religiosas protestantes y su tránsito hacia lo político-electoral en Colombia, 1990-2007. Revista Mexicana de Sociología, 72(1), 73-111.

Duque, J. (2017). Las urnas contaminadas: Elecciones, fraude y manipulación en la democracia colombiana 1990 - 2015. Medellín: Editorial La Carreta.

Duque, J. (2018). La doble vuelta en las elecciones presidenciales en Colombia 1994 -2018: La búsqueda esquiva de mayor legitimidad y de consensos. Civilizar: Ciencias Sociales Y Humanas, 19(36), 77-102. https:// doi.org/10.22518/usergioa/jour/ccsh/2019.1/a05

Duverger, M. (1954). Los partidos políticos. México D. F.: Fondo de Cultura Económica.

El País (3 de febrero de 2006). La popularidad de uribe asciende al 72\% cuatro meses antes de las elecciones. Recuperado de: https:// elpais.com/ internacional/2006/02/03/actualidad/1138921201_850215.html

Greenberg, J., \& Shlomo, W. (1985). Multiparty Equilibria under Proportional Representation. American Political Science Review, 79, 693-703. https://doi.org/10.2307/1956838

Grum, J. (1958). Theories of Electoral Systems. Midwest Journal of Political Science, 2(4) 357-376. https://doi.org/10.2307/2108721

Gutiérrez Sanín, F. (2000). Politicians and Criminals: Two Decades of Turbulence, 1978-1998. International Journal of Politics and Society, 14(1), 71-87. https://doi.org/10.1023/A:1007813129882

Harmel, R., \& Robertson, J. D. (1985). Forrnation and Success of New Parties: A Cross-National Analysis. International Political Science Review, 6(4). https://doi.org/10.1177/019251218500600408

Hartlyn, J. (1989). La política del régimen de coalición. La experiencia del Frente Nacional en Colombia. Bogotá: Centro de Estudios Internacionales de la Universidad de los Andes (CEI), Ediciones Uniandes, Tercer Mundo Editores. 
Horowitz, D. (1985). Ethnic Groups in Conflict, Updated Edition with a New Preface. Berkeley: California University Press.

Jones, M. (1999). Electoral Laws and the Effective Number of Candidates in Presidential Elections. The Journal of Politics 61(1), 171-184. https:/ / doi.org/10.2307/2647780

Jones, M. (2004). Electoral Institutions, Social Cleavages, and Candidate Competition in Presidential Elections. Electoral Studies 23(1), 73-106. https://doi.org/10.1016/S0261-3794(02)00056-2

Kim, J-O., \& Ohm, M. (1992). A Theory of Minor-Party Persistence: Election Rules, Social Cleavage, and the Number of Political Parties. Social Forces, 70(3), 575-579. https://www.doi.org/10.2307/2579745

Laakso, M., \& Taagepera, R. (1979). "Effective" Number of Parties: A Measure with Application to West Europe. Comparative Political Studies 12(1), 3-27. https://doi.org/10.1177/001041407901200101

Leal, F., \& Dávila, A. (1990). Clientelismo: El sistema politico y su expresión regional. Bogotá: Tercer Mundo, Instituto de Estudios Políticos y Relaciones Internacionales (IEPRI).

Lijphart, A. (1994). Electoral Systems and Party Systems: A Study of Twenty-Seven Democracies, 1945-1990. Nueva York: Oxford University Press. https:// doi.org/10.1093/acprof:oso/9780198273479.001.0001

Lipset, S. M., \& Stein, R. (1967). Cleavage structures, party systems, and voter alignments: An introduction. En S. M. Lipset \& S. Rokkan (Eds.), Party systems and voter alignments: Cross-national perspectives (págs. 1-64). Nueva York: The Free Press.

López, C., \& Sevillano, Ó. (2008). Balance político de la parapolítica. Fundación Ideas para la Paz. Recuperado de http://www.ideaspaz.org/ tools/download/54297

Losada Lora, R. (1984). Clientelismo y elecciones: tres modelos explicativos del comportamiento electoral colombiano. Bogotá: Pontificia Universidad Javeriana. Losada, R., \& Vélez, E. (1982). Identificación y participación política en Colombia. Bogotá: Fundación para la Educación Superior y el Desarrollo (FEDESARROLLO).

Luján, D. (2017). El costo de coordinar: número de candidatos presidenciales en América Latina 1993-2010. Revista de Ciencia Politica (Santiago), 37(1), 25-46. https://doi.org/10.4067/S0718-090X2017000100002

Mainwaring, S., \& Shugart, M. (Eds.). (1997). Presidentialism and Democracy in Latin America. Cambridge: Cambridge University Press. 
Medina Gallego, C. (1990). Autodefensas, Paramilitares y Narcotraficantes en Colombia. Bogotá: Editorial Documentos Periodísticos.

Moser, R., \& Scheiner, E. (2012). Electoral Systems and Political Context. How the Effects of Rules Vary Across New and Established Democracies. Nueva York: Cambridge University Press.

Muñoz, B. (2015). Las candidaturas independientes en América Latina: repasando las reformas, sus ventajas y los retos pendientes. Perfil de Betilde MuñozPogossian en Reformas Políticas en América Latina. Recuperado de https://reformaspoliticas.org/reformas/candidaturas/candidaturasindependientes/betilde-munoz-pogossian/be

Myerson, R. B., \& Weber, R. J. (1993). A theory of voting equilibria. American Political Science Review, 87(1) 102-114. https:/ / doi.org/10.2307/2938959

Nohlen, D. (1993). Capítulo 3. Sistemas electorales de América Latina. En Presidencialismo, Sistemas Electorales y Sistemas de Partidos. Lima: Fundación Friedrich Ebert.

Nohlen, D. (1996). Elections and Electoral Systems. Nueva Delhi: Macmillan.

Nohlen, D., \& Fernández, M. (1998). Presidencialismo, Sistemas electorales y sistemas de partidos. En D. Nohlen \& M. Fernández, El presidencialismo renovado: Instituciones y cambio político en América Latina. Caracas: Nueva Sociedad.

Palfrey, T. (1989). A Mathematical Proof of Duverger's Law. En: P. C. Ordeshook. (Ed.), Models of Strategic Choice in Politics (pp. 69-91). Ann Arbor: University of Michigan Press.

Rae, D. (1971). The Political Consequences of Electoral Laws. New Haven: Yale University Press.

Riker, W. (1982). The Two-Party System and Duverger's law: An Essay on the History of Political Science. American Political Science Review 76(4), 753-766. https://doi.org/10.2307/1962968

Rose, R., \& Urwin, D. (1970). Persistence and Change Western Party Systems Since 1945. Political Studies, 18(3), 287-319. https://doi. org/10.1111/j.1467-9248.1970.tb00436.x

Sani, G., \& Sartori, G. (1983). Polarization, Fragmentation and Competition in Western democracies. En H. Daalder \& P. Mair (Eds.), Western European Party Systems: Continuity and Change (pp. 307-340). Londres: Sage Publications. 


\section{I JaVier Duque Daza}

Shugart, M. S., \& Argueta Sandoval, J. P. (2007). Mayoría relativa vs. segunda vuelta La elección presidencial mexicana de 2006 en perspectiva comparada. Politica y gobierno, 14(1), 175-202.

Shugart, M. S., \& Carey, J. M. (1992). Presidents and Assemblies: Constitutional Design and Electoral Dynamics. Cambridge University Press.

Taagepera, R., \& Shugart, M. S (1989). Seats and Votes: The Effects and Determinants of Electoral Systems. New Haven: Yale University Press.

Thoumi, F. (1993). Economía política y narcotráfico. Bogotá: Tercer Mundo editores.

Uprimny, R. (1989). Legitimidad, clientelismo y política en Colombia. Un ensayo de interpretación. Cuadernos de Economía, 10(13), 113-164. https://doi.org/10.15446/cuad.econ

Vélez, C., Ossa, J. P., \& Montes, P. (2006). Y se hizo la Reforma... Condiciones que permitieron el trámite exitoso de la reforma política del 2003. En G. Hoskin \& M. García, La reforma política de 2003. ¿La salvación de los partidos políticos colombianos? (pp. 1-29). Bogotá: Universidad de los Andes. 